\title{
Dynamic Characteristic and Power Consumption on an Electro-Pneumatic Hybrid Positioning System
}

\author{
Hiroshi HIGO*, Yasuo SAKURAI**, Takeshi NAKADA***, \\ Kazuhiro TANAKA*, and Katsuya NAGAYAMA* \\ * Department of Mechanical Information Science and Technology, \\ Kyushu Institute of Technology \\ 680-4 Kawatsu, Iizuka, Fukuoka, 820-8502 Japan \\ ** Department of Mechanical Engineering, \\ Ashikaga Institute of Technology \\ 286-1 Oomae, Ashikaga, Tochigi, 326-8558 Japan \\ *** Department of Environment Integration and design, \\ Tokyo Denki University \\ 2-1200 Muzaigakuendai, Inzai, Chiba, 270-1382 Japan
}

\begin{abstract}
This paper deals with the dynamic characteristics of an electro-pneumatic hybrid positioning system. This system is composed of a pneumatic, an electric and a mechanical driving sub-system. The pneumatic driving system controls the pressure supporting the inertial mass, which means that the pressure is correspondent to the gravitational force acting on it. And the electric driving system with small capacity moves the inertial mass vertically through a ball screw as a mechanical driving sub-system. In the present study, in order to developing the electro-pneumatic hybrid positioning system, the mathematical model of this system has been refined by comparing calculation data with the experimental results, especially by measuring precisely frictional force of the ball screw. And the power consumption as well as the dynamic characteristics has been investigated numerically when the inertial mass is moved vertically upwards and downwards during one cycle by the electric driving system through the ball screw. The data on the power consumption during one cycle will be useful to select a suitable driving motor at the design stage.
\end{abstract}

\section{KEY WORDS}

Electro-pneumatic hybrid positioning system, Dynamic characteristics, Pressure control, Bondgraphs, Modeling

\section{NOMENCLATURE}

$A e:$ Effective area of the cylinder

$A_{r}$ : Area of rod side cylinder

$A_{h}:$ Area of head side cylinder

$C$ : Frictional loss coefficient

$F$ : Force

$k$ : Specific heat ratio

$K$ : Rigidity of coupling

Iz : Momentum of shaft

$l$ : Lead of ball screw

$\dot{m}$ : Mass flow rate

$M$ : Inertial mass

$P$ : Pressure

$Q$ : Flow rate

$R$ : Gas constant

$T$ : Temperature $\left[\mathrm{m}^{2}\right]$

$\left[\mathrm{m}^{2}\right]$

$\left[\mathrm{m}^{2}\right]$

$[\mathrm{Ns} / \mathrm{m}]$

[N]

[-]

[Nm/rad]

$\left[\mathrm{kgm}^{2}\right]$

[m]

[kg/s]

[kg]

$[\mathrm{Pa}]$

$\left[\mathrm{m}^{3} / \mathrm{s}\right]$

$[\mathrm{J} /(\mathrm{kgK})]$

[K] $v$ : Velocity

$[\mathrm{m} / \mathrm{s}]$

$\omega$ : Rotational speed

$[\mathrm{rad} / \mathrm{s}]$

$\tau:$ Torque

$[\mathrm{Nm}]$

\section{INTRODUCTION}

A pneumatic system has some advantages such as safety, ease to maintenance, environment, and so on. Then the pneumatic system is used various automation machines. However, the pneumatic system is difficult to control velocity and positioning of an inertial mass precisely [1-2]. To improve these disadvantages, an electro-pneumatic hybrid system is proposed [3]. In this system, supplied air pressure supports an inertial mass and the positioning of the inertial mass is controlled by a servomotor. This mechanism can easily control the positioning of the inertial mass more precise than a 
pneumatic system.

However, when this actuator moves with suddenly large inertial mass, the servomotor faces unpredictably large torque and stops automatically. To avoid this stopping, it is important to predict the load of the servomotor precisely by analyzing the dynamic characteristics of the system.

Bondgraph method is very convenient to predict the system dynamic characteristics and calculate power consumption. The method is available in various systems composed mechanical, electrical and hydraulic components because it is based on the viewpoint of power conservation. This method has been used for prediction of dynamic characteristics and designing real systems [4-6]. In order to establish a design method of an electro-pneumatic hybrid system, the Bondgraph method is surely useful.

The objectives of this study are followings.

1. To investigate frictional loss of the electro-pneumatic actuator by experiment.

2. To construct a mathematical system model of the electro-pneumatic actuator.

3. To compare experimental results with calculated results when this actuator is operated and to verify the mathematical model of the system.

\section{ELECTRO-PNEUMATIC ACTUATOR}

Figure 1 shows the electro-pneumatic hybrid actuator. The Electro-pneumatic actuator consists of a servomotor, a cylinder, a ball screw, a rod and a air supply system. The servomotor is combined with the ball screw. The rod is combined with the nut. The bottom part of ball screw is inside the rod, when the servomotor is driven, the ball screw rotates, the nut moves and the inertial mass also moves.

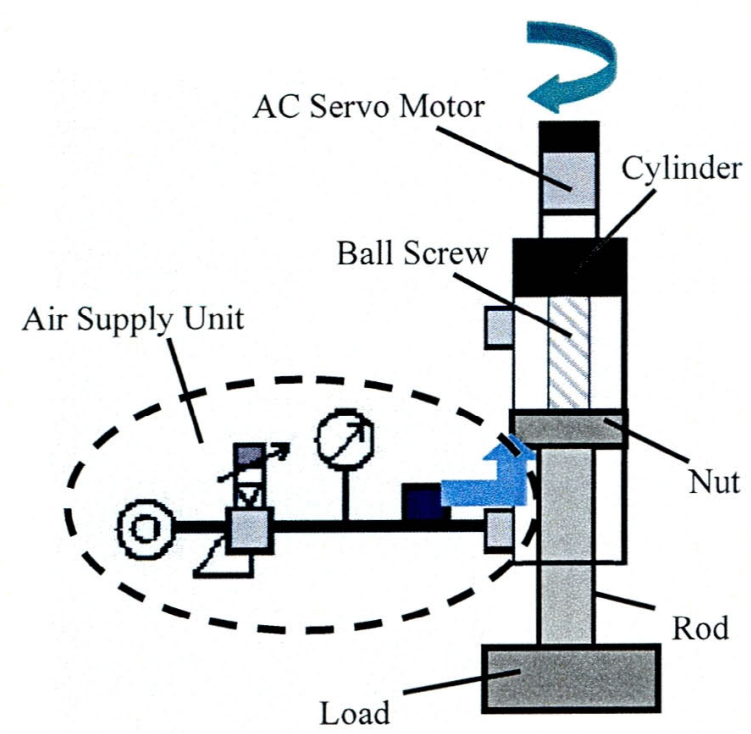

Fig. 1 Schematic of Electro-pneumatic actuator
The pressure of air supply system is correspondent to gravitational force acting on an inertial mass. Therefore, even a servo motor with low-capacity can control a large inertial mass.

\section{EXPERIMENTAL EQUIPMENT}

Experimental equipment is shown in Fig. 2. The pressure of the air supply unit is controlled by an electric-pneumatic regulator and is provided into the rod side of the cylinder. The pressure of another side chanber is atmospheric pressure. PC controls the electro-pneumatic regulator and angular velocity of the servomotor for precise positioning. In the experiment torque and rotational degree of the servomotor are measured.

\section{SIMULATION MODEL}

Generally, a physical system consists of electrical, mechanical, fluid, thermal system and so on. Because power flows between elements in physical systems, the systems can be expressed using power train. Bondgraph method is one of the system expression method based on power train.

When power flows from a system to a sub-system, these two elements can be connected by a line, called bond, which indicates power flow, as shown in Fig.3. Power is the product of effort and flow variables in each system, shown in Table 1. Consequently, the power bond has two power variables, effort and flow. In Bondgraph method, an element indicates a physical quantity in each field, shown as Table 2 .

Table1 Variables

\begin{tabular}{|l|l|l|l|}
\hline & $\begin{array}{l}\text { Rectilinear } \\
\text { system }\end{array}$ & $\begin{array}{l}\text { Rotational } \\
\text { system }\end{array}$ & $\begin{array}{l}\text { Fluid } \\
\text { system }\end{array}$ \\
\hline Effort & Force & Torque & Pressure \\
\hline Flow & Velocity & $\begin{array}{l}\text { Angular } \\
\text { Velocity }\end{array}$ & $\begin{array}{l}\text { Volume } \\
\text { flow rate }\end{array}$ \\
\hline
\end{tabular}

Table2 Elements

\begin{tabular}{|l|l|l|l|}
\hline Element & $\begin{array}{l}\text { Mechanical } \\
\text { system }\end{array}$ & $\begin{array}{l}\text { Rotational } \\
\text { system }\end{array}$ & Fluid system \\
\hline SE & Force & Torque & Pressure \\
\hline SF & Velocity & $\begin{array}{l}\text { Angular } \\
\text { Velocity }\end{array}$ & $\begin{array}{l}\text { Volume flow } \\
\text { rate }\end{array}$ \\
\hline R & Friction & Friction & $\begin{array}{l}\text { Fluid } \\
\text { Friction }\end{array}$ \\
\hline I & $\begin{array}{l}\text { Mass } \\
\text { inertia }\end{array}$ & $\begin{array}{l}\text { Momentum } \\
\text { inertia }\end{array}$ & Mass inertia \\
\hline C & Spring & Spring & Capacity \\
\hline
\end{tabular}




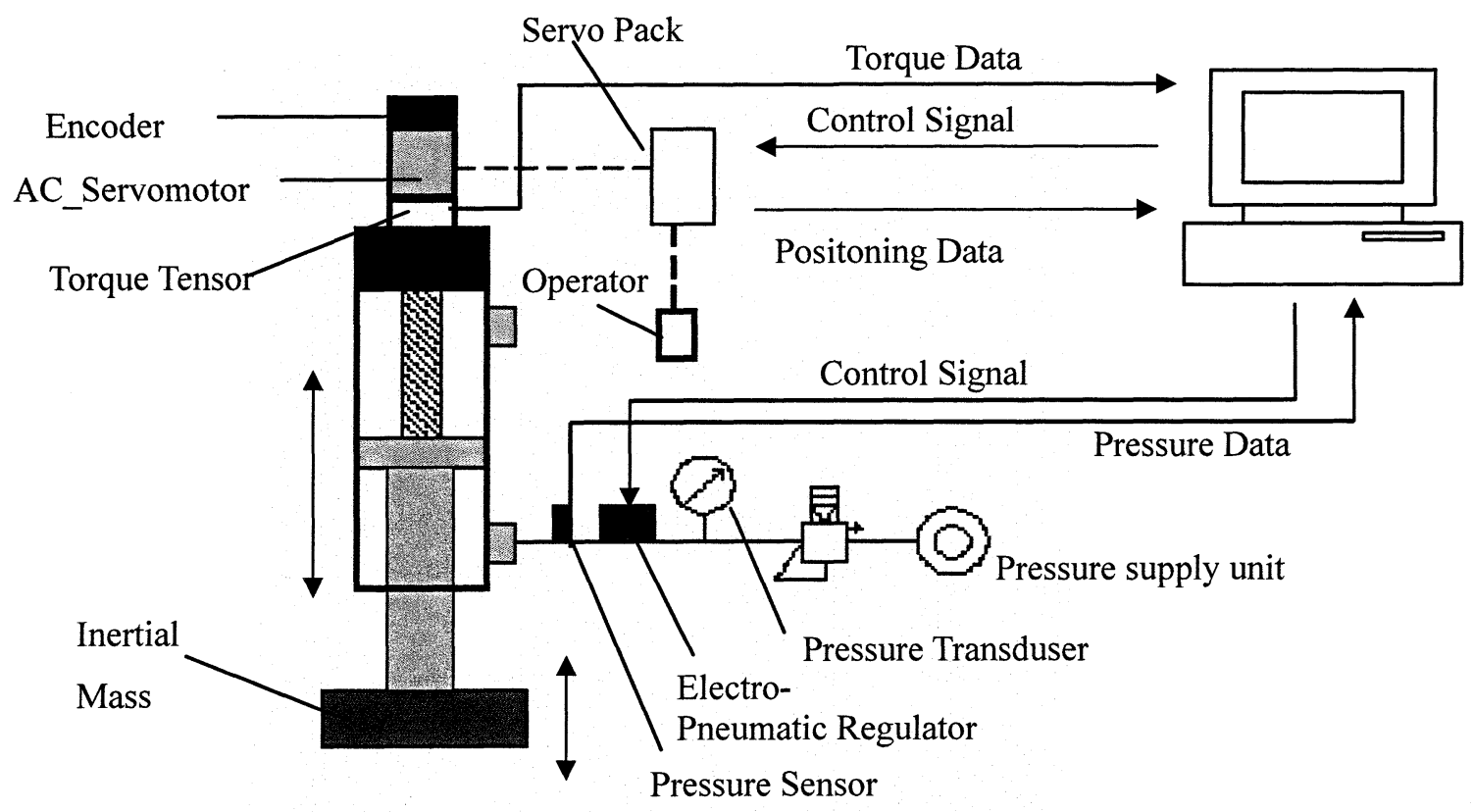

Fig. 2 Experimental apparatus

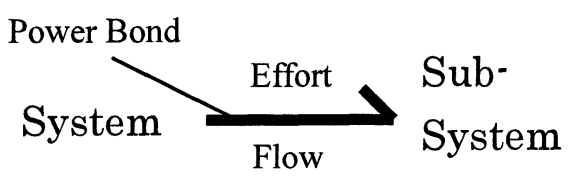

Fig. 3 Bond

A system bondgraph model of the electro-pneumatic actuator is shown in Fig. 4.

Output pressure of an air supply unit is assumed to be constant. Then an air supply unit is modeled by 'Se: Air supply unit' element. The following equation can be used for this element.

$$
P_{1}=\text { const }
$$

Subscript indicates the number of bond.

An electric-pneumatic regulator is modeled by ' $R$ : Valve' element and its constitutive equation is expressed as follows.

$$
\left(0 \leq \frac{P_{3}}{P_{1}}<0.528\right)
$$

$$
\begin{aligned}
& \dot{m}_{2}=A_{e} P_{1} \sqrt{\frac{\kappa}{R T_{1}}\left\{\left(\frac{2}{\kappa+1}\right)^{\frac{\kappa+1}{\kappa-1}}\right\}} \\
& \left(0.528 \leq \frac{P_{3}}{P_{1}} \leq 1\right)
\end{aligned}
$$

$$
\dot{m}_{2}=A_{e} P_{1} \sqrt{\frac{2 \kappa}{\kappa-1} \frac{1}{R T_{1}}\left\{\left(\frac{P_{3}}{P_{1}}\right)^{\frac{2}{\kappa}}-\left(\frac{P_{3}}{P_{1}}\right)^{\frac{\kappa+1}{\kappa}}\right\}}
$$

Where Ae is effective area of the electric-pneumatic regulator, $P_{1}$ is pressure of air supply unit, $T_{1}$ is temperature of air.

' $\mathrm{C}$ : Compressibility' element means compressibility of the air in the rod end chamber of the pneumatic cylinder. Its constitutive equation is expressed as follows.

$$
P_{4}=\frac{\kappa}{V_{0}+A x} \int\left(R T_{t-1} \dot{m}-P_{t-1} A v\right) d t+P_{0}
$$

Where $P_{0}$ is initial pressure of rod-end chamber, $V_{0}$ is initial volume of rod-end chamber, $T_{t-1}$ is calculation 


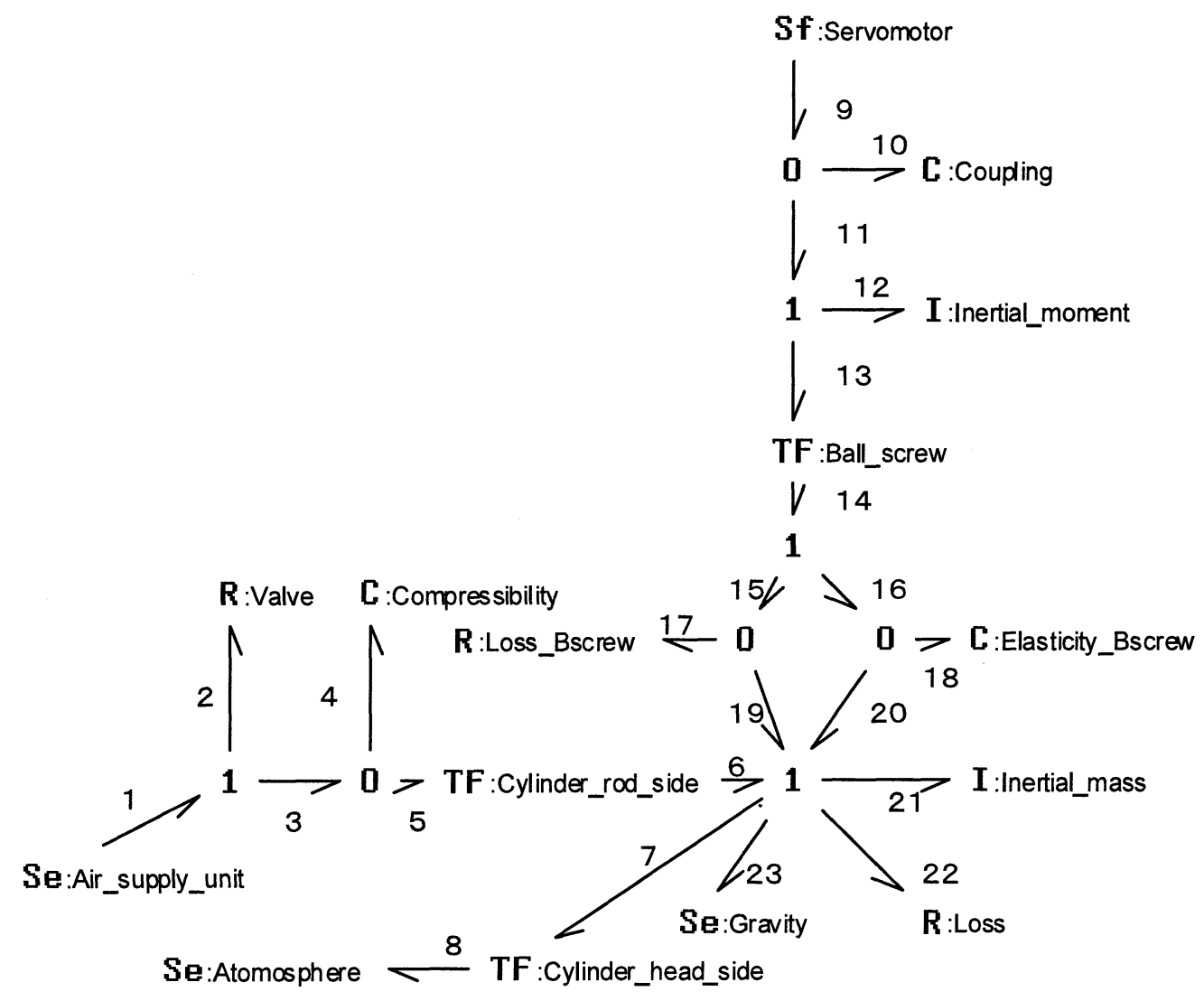

Fig. 4 System bondgraph model

result of temperature, $\mathrm{P}_{\mathrm{t}-1}$ is calculation result of pressure. Each variable are calculational results before 1time step.

'TF1:Cylinder_head_side', 'TF1: Cylinder_rod_side' mean pressure area of piston, and its constitutive equation is expressed as follows

$$
\begin{aligned}
& F_{6}=A_{r} P_{5} \\
& Q_{5}=A_{r} v_{6} \\
& F_{7}=A_{h} P_{8} \\
& Q_{8}=A_{h} v_{7}
\end{aligned}
$$

Where $A_{r}$ is area of rod side chamber, $A_{h}$ is area of head side chamber. By these elements, pressure is changed mechanical force.

'SF: Servomotor' element represents angular velocity of a servomotor. The objective of present study is to establish a mathematical model of an electro-pneumatic hybrid positioning system. Therefore, the accurate mathematical model of the servomotor was not derived.
Angular velocity $\omega_{9}$ is measured in experiment and used as an input to the system in simulation.

' $\mathrm{C}$ : Coupling' element means the torsion rigidity of the coupling, this equation is represented as follows.

$$
\tau_{10}=K \int \omega_{10} d t
$$

where $\mathrm{K}$ is rigidity of coupling.

'I: Inertial_moment' element means moment of ball screw. This equation is represented as follows

$\omega_{12}=\frac{1}{I_{z}} \int \tau_{12} d t$

where $\mathrm{Iz}$ is the inertial momentum of shaft

A ball screw is represented by 'TF: Ball screw' element for change from rotation motion to liner motion, and its constitutive equation is expressed as follows

$v_{14}=\frac{l}{2 \pi} \omega_{13}$ 
$\tau_{13}=\frac{l}{2 \pi} F_{14}$

where $l$ is lead of ball screw.

'R: Loss_Bscrew' and 'C: Elasticity_Bscrew' element mean the characteristic of a nut.

'I: Inertial mass' means an inertial mass. This constitutive equation is expressed as follows

$v_{21}=\frac{1}{M} \int F_{21} d t$

' $R$ : Loss' means frictional loss of cylinder. It is difficult to decide a frictional loss of a cylinder from using only parameters of equipment. Accordingly, this parameter is measured by experiment. Therefore this constitutive equation is expressed as

$F_{22}=C \cdot v_{22}\left(v_{22}<-0.01\right.$ or $\left.0.01<v_{22}\right)$

$F_{22}=$ const. $\left(-0.01<v_{22}<0.01\right)$

'Se: Gravity' indicates gravity force of an inertial mass. It is constant value.

$F_{23}=M g$

\section{RESULTS AND DISCUSSION}

\section{Frictional loss}

Frictional force is measured by experiments. The pressure which is controlled by an electric-pneumatic regulator is set at the constant value correspondent to the gravitational force of an inertial mass. By rotating the servomotor, an inertial mass moves upwards or downwards. The relationship between force of the cylinder and moving velocity of the inertial mass is followings.

$\mathrm{F}$, force of the nut is calculated by pressure $\mathrm{P}$, torque $\tau$ and inertial mass M (Eq.(17)). Pressure and torque were measured. The coefficient of frictional force is calculated by Eq.(18).

$F=\frac{2 \pi}{l} \tau+P A_{e}-M g$

$C=\frac{F}{v}$

Fig. 5 shows the measured results of the frictional force. It can be seen from this figure that the frictional loss is affected by the velocity of inertial mass.
Relationship between the velocity and frictional coefficient is expressed as

$$
\begin{array}{ll}
C=213.7 v^{-0.79} & \text { (Upward) } \\
C=179.0 v^{-0.86} & \text { (Downward) }
\end{array}
$$

The frictional coefficient used here was taken from the experiment and was placed $\mathrm{R}$ element for the simulation.

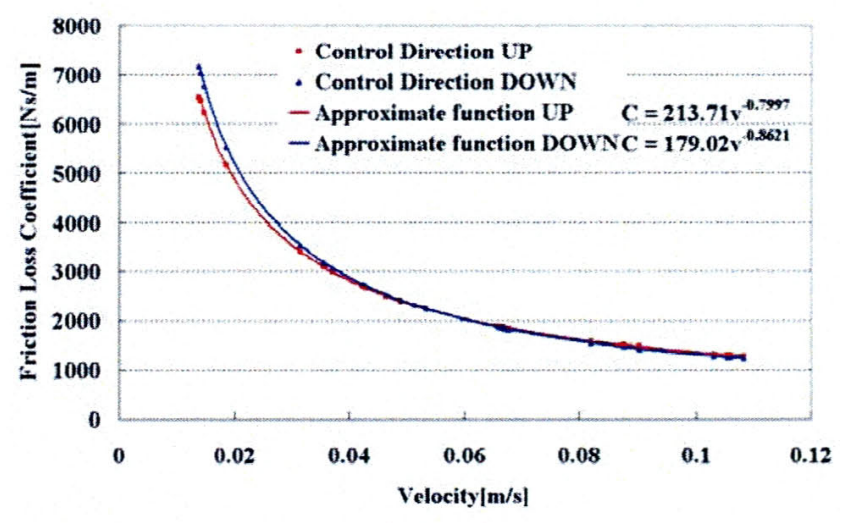

Fig. 5 Frictional Loss

\begin{tabular}{|c|c|}
\hline Parameter & Value \\
\hline Valve effective area & $6.0 \times 10^{-5}$ \\
\hline Estimated valve effective area $\quad\left[\mathrm{m}^{2}\right]$ & $1.2 \times 10^{-5}$ \\
\hline Ratio of the specific heat of the air $[-]$ & 1.4 \\
\hline Initial temperature $[\mathrm{K}]$ & 293 \\
\hline Gas constant $[\mathrm{J} / \mathrm{kg} \mathrm{K}]$ & 287.3 \\
\hline Cross sectional area of the cylinder $\left[\mathrm{m}^{2}\right]$ & $2.63 e-3$ \\
\hline Initial volume of the cylinder $\left[\mathrm{m}^{3}\right]$ & $2.63 \mathrm{e}-4$ \\
\hline Initial pressure [MPa] (absolute) & 0.224 \\
\hline Inner diameter of the cylinder tube [m] & $6.3 \times 10^{-2}$ \\
\hline Diameter of the cylinder rod [m] & $2.5 \times 10^{-2}$ \\
\hline Weight $[\mathrm{kg}]$ & 31.7 \\
\hline Constant dynamic friction $[\mathrm{Ns} / \mathrm{m}]$ & 160 \\
\hline Friction loss coefficient (UP) [Ns/m] & $706.59 \mathrm{v}^{-0.73}$ \\
\hline Friction loss coefficient (DOWN) $[\mathrm{Ns} / \mathrm{m}]$ & $435.61 \mathrm{v}^{-0.66}$ \\
\hline Elasticity of the nut (Gap $\geq 0.1[\mathrm{~mm}])$ & $1.1 \times 10^{8}$ \\
\hline Gap ( Damper coefficient ) [Ns/m] & $1.0 \times 10^{5}$ \\
\hline Lead of the ball screw $[\mathrm{m} / \mathrm{r}]$ & $5.0 \times 10^{-3}$ \\
\hline Inertial moment $\left[\mathrm{kgm}^{2}\right]$ & $4.06 \times 10^{-5}$ \\
\hline $\begin{array}{l}\text { Rotational elasticity of the coupling } \\
{[\mathrm{Nm} / \mathrm{rad}]}\end{array}$ & 120.9 \\
\hline
\end{tabular}

Table3 Experimental Parameters

\section{Dynamic characteristics and power consumption}

The experiment of dynamic characteristic of the 
electro-pneumatic actuator is performed. Prior to the experiment, the position of the inertial mass was set at the lowest point and the control of the pressure acting on the inertial mass was started.

The input signal to determine angular velocity of servomotor was added to the servomotor controller. And then, inertial mass moved upwards by $100 \mathrm{~mm}$, then stopped, and moved downwards by $100 \mathrm{~mm}$. These experiments were carried out at same angular velocities of the servomotor. Experimental results are inputted as the angular velocity in the simulation. Table 3 shows experimental parameters. Only parameters of friction loss coefficient and input angular velocity are the experimental data and the others are catalogue value.

Simulation and experimental results are shown in Fig. 6 . It can be seen from this figure that the experimental result and calculation result are agree well when inertial mass is moved. However, when inertial mass is stopping, calculation result is different from experimental ones. It might be thought that static friction at a moment when the servomotor stops is different in each case of experiments. When the mass moves downwards, the calculation data is stable compared with experimental data. This is because the capacity of the electro-pneumatic regulator is not suitably determined. If new regulator with more capacity is used, the both data will agree well. Any well, the data comes to a close match with an only minor discrepancy.

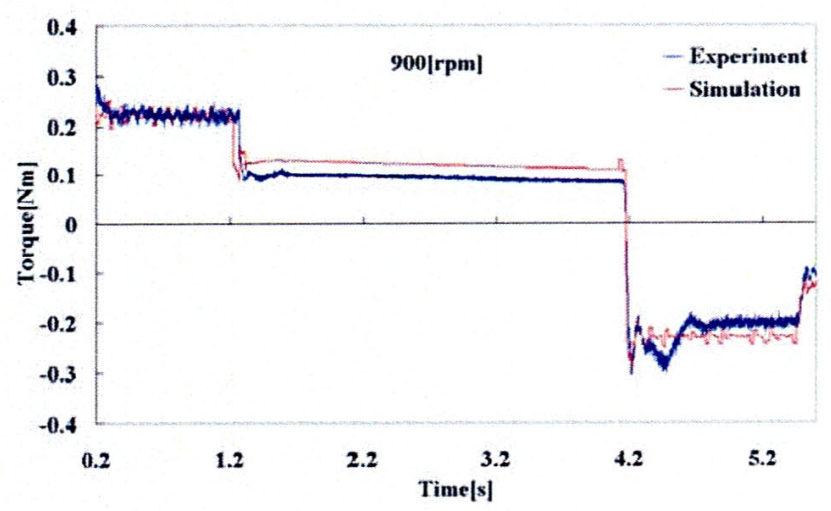

Fig. 6 Torque

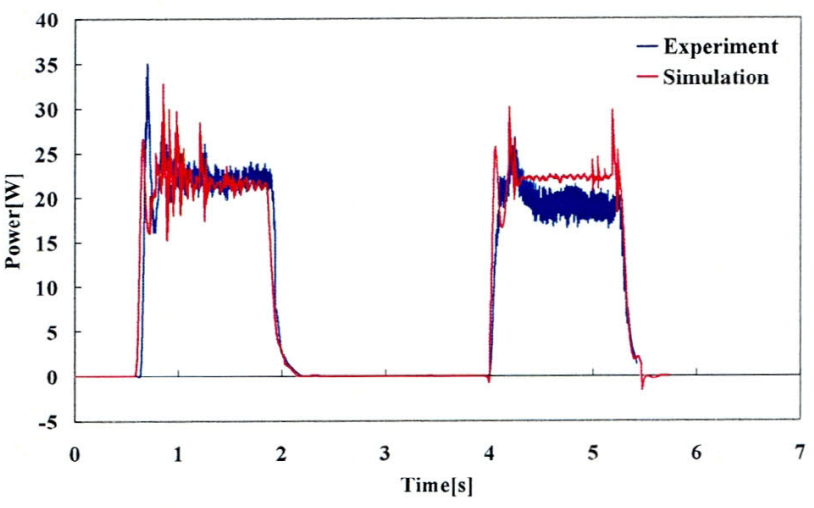

Fig. 7 Power of servomotor

Fig. 7 is comparison of calculation results with experimental ones on servomotor power. From this figure, calculation result and experimental one are agree well. Therefore, it is seemed that this model can predict the power of servomotor of electro-pneumatic hybrid actuator.

\section{CONCLUSION}

The mathematical model of the electro-pneumatic hybrid actuator was proposed to predict the system dynamic characteristics and power consumption. The frictional loss of the actuator, which is the most difficult parameter to be determined in the system, was measured precisely at moving upwards and downwards during the cycle. As a result, calculation result agrees well with experimental results. This proved that this mathematical model can predict dynamic behaviors of the system and the power of servomotor.

\section{ACKNOWLEDGEMENT}

The authors would like to thank SMC Co, Ltd. for providing the experimental apparatus and helpful suggestions.

\section{REFERENCES}

1. SHIH, Ming chang and LUOR, Niarn-liarng. Self-tuning Neural Fuzzy Control the Position of a Pneumatic Cylinder Under Vertical Load. Proc of $6^{\text {th }}$ FLUCOME, Sherbrooke CANADA, Cd-ROM, 2000.

2. Baihai ZHANG, Bondgraph Modeling and Simulation of Dynamic Characteristics of a Pneumatic System with an Air Cushion Cylinder, $5^{\text {th }}$ JFPS International Symposium, 339-342, (2002).

3. Y.SAKURAI, K.TANAKA, T.NAKADA, Dynamic Characteristic On An Electro-Pneumatic Hybrid Positioning System, $7^{\text {th }}$ Int. Symp. on Fluid Control, Measurement and Visualization, 2004

4. E. Benjamin Wylie, Victor L. Streeter, Fluid Transient in Systems, p. 2-9, PRENTICE HALL 1993.

5. Rosenberg R.C. and Karnopp D.C. Introduction to Physical System Dynamics, McGraw-Hill, 1983.

6. Thoma J. Simulation by Bondgraphs, Springer-Verlag, 1990. 